\title{
Proyecto de ley de Régimen Jurídico de las Administraciones Públicas y Procedimiento Administrativo Común
}

\section{Bill of Legal System from Public Administration and the common administrative procedure}

\author{
KARLOS NAVARRO*
}

Resumen: Este artículo pretende mostrar cuál ha sido el proceso de elaboración del proyecto de ley de régimen jurídico de las administraciones públicas, quiénes participaron de él, cómo quedó estructurado y cuáles serán los retos que traerá su aprobación.

Palabras clave: Constitución - procedimiento administrativo - acto administrativo

Abstract: This article aims to present the process of drafting the Bill of Legal System from Public Administration, who were the participants, how it was organized and which are the challenges to face in the future to pass the bill.

Key words: Constitution - Administrative Procedure - Administrative Action

CONTENIDO: I. LA CONSTITUCIÓNY EL PROCEDIMIENTO ADMINISTRATIVO.II. SURGIMIENTO DE LA PROPUESTA DELEY DERÉGIMEN JURÍDICO DE LAS ADMINISTRACIONES PÚBLICASY PROCEDIMIENTO ADMINISTRATIVO COMÚN.III. ELABORACIÓN DEL PROYECTO DE LEY. CONTENIDO Y ESTRUCTURA DEL PROYECTO DE LEY.- IV. CONTENIDO Y ESTRUCTURA DEL PROYECTO DE LEY.

\section{LA CONSTITUCIÓN Y EL PROCEDIMIENTO ADMINISTRATIVO}

En la Constitución nicaragüense de 1987 y en las sucesivas reformas, no aparece de forma explícita un artículo sobre la administración pública. Este fenómeno es un tanto extraño. La explicación es, sin embargo, bien sencilla: en Nicaragua ha existido desde siempre una muy difusa

\footnotetext{
* Doctor en Derecho administrativo, Universidad de Salamanca, España. Coordinador de Postgrado de Derecho, Universidad Nacional Autónoma de Nicaragua.

1 Durante los años que estudié y elaboré la tesis de doctorado en Derecho administrativo en la Universidad de Salamanca, el doctor Jaime Rodríguez Arana y Miguel Ángel Sendin influyeron notablemente en mí a fin de hacerme notar la importancia de lo que significaba la elaboración de un proyecto de ley del Régimen Jurídico de las Administraciones Públicas y Procedimiento Administrativo Común para la gobernabilidad, la defensa de los derechos de los ciudadanos y la modernidad del Estado de Nicaragua. Años después, se dio la oportunidad de elaborar este proyecto de ley, y Jaime y Miguel lo apoyaron desde el inicio, involucrándose activa y entusiastamente en su redacción. A ellos le doy mi agradecimiento.
} 
- y en muchos casos, inexistente- separación entre gobierno y administración.

Esta situación es fruto y causa de la inestabilidad política y social que ha acusado el Estado nicaragüense a lo largo de su historia. Por lo que se refiere a lo primero, la rápida y traumática sucesión de regímenes políticos contradictorios ha dado al traste con toda posible tentativa de formar un aparato administrativo estable y neutral.

Este fracaso en la construcción de un substrato burocrático no politizado ha sido, por otro lado, una pesada losa a la hora de buscar soluciones a la delicada coyuntura político-social de este país. La utilización de los puestos públicos como una vía de recompensa para los acólitos en el poder - en la más pura tradición del spoil system, a la que ha dado lugar el clientelismo vigente durante décadas — ha contribuido a radicalizar una vida política ya de por sí agitada en grado extremo, y ha dificultado notablemente que los cambios en el poder político discurriesen de forma serena y calmada.

Sabido es que una administración pública sólida y estable minimiza notablemente los problemas políticos, ya que otorga protección mínima a los ciudadanos — aunque sea a nivel administrativo_- y permite un funcionamiento continuado de los servicios públicos, que, como cuestión eminentemente técnica, no se ve afectada —al menos en parte importante — por las disputas ideológicas y partidistas.

De ninguna de estas ventajas ha disfrutado, por desgracia, una Nicaragua que se ha visto envuelta en un trágico círculo vicioso, en la que los vaivenes políticos han destrozado todos los intentos por conseguir una mínima estabilidad social y económica.

En los últimos tiempos, estamos asistiendo a nivel de derecho ordinario a una esperanzadora introducción de un régimen administrativo avanzado, equiparable en sus aspectos esenciales al que rige en las naciones más desarrolladas del planeta. Aunque su instauración práctica va a encontrar — está de hecho encontrando— grandes y múltiples dificultades - falta de capacitación del personal administrativo, ausencia de una doctrina y tradición administrativa, falta de medios materiales, excesiva politización de las instancias administrativas, etcétera-, constituye un paso gigante para la normalización política y social de este país.

Sin embargo, el funcionamiento del sistema administrativo integrado en sus elementos principales por la Ley de Regulación de la Jurisdicción de lo Contencioso-Administrativa (ley 350), por la Ley de Servicio Civil y de la Carrera Administrativa (ley 370), y por la Ley de Contrataciones del Sector Público (ley 737), estaba ya seriamente perturbado sin que se le adicionara este elemento central, y se mostraba como un edificio 
majestuoso, pero débil, por faltarle justamente su viga maestra: la Ley de Régimen Jurídico de las Administraciones Públicas y Procedimiento Administrativo Común.

\section{II.SURGIMIENTO DE LA PROPUESTA DE LEY DE RÉGIMEN JURÍDICO DE LAS ADMINISTRACIONES PÚBLICAS Y PROCEDIMIENTO ADMINISTRATIVO COMÚN}

La idea de elaborar una Ley de Régimen Jurídico de las Administraciones Públicas y Procedimiento Administrativo Común surgió, en primer lugar, como producto de una necesidad de dar a los administrados un trato similar y no discriminatorio, similar al que reciben en la actualidad producto de la utilización de una multiplicidad de normas dispersas y carentes de coherencia y unidad. Esto también ocurre debido a la intención de garantizar los derechos de los ciudadanos y la eficacia de la actividad administrativa.

Además, es evidente que una ley de este tipo brinda una mayor confianza de la ciudadanía en el funcionamiento de la administración, ya que permite a aquella conocer que esta no actúa de forma arbitraria y según sus deseos, sino siguiendo un discurrir prefijado y adecuado a las necesidades que tiene que resolver, lo que provoca que vea en ella un ente encargado de la aplicación del ordenamiento jurídico, y no un arbitrario poder que decide según su propia voluntad.

Esta propuesta surgió también para garantizar el mayor acierto de las decisiones administrativas y encauzar el funcionamiento de la administración pública, al obligarla a seguir una línea de actuación ordenada y sistemática, además de para fomentar la participación de los ciudadanos en el desarrollo de las tareas administrativas y para garantizar la transparencia en el desarrollo de estas. Una ley de este tipo tiene entre sus principales contenidos la regulación de los procedimientos, trámites y derechos de los administrados, a través de los que se les permite tomar conocimiento de la actuación desarrollada por la administración y hacer llegar su voz a los administrados de forma efectiva.

A lo largo de la historia del Derecho administrativo nicaragüense se ha carecido de una ley única que regule el procedimiento administrativo, razón por la que, tradicionalmente, dicha materia ha sido regulada por una normativa dispersa e incoherente, lo que ha provocado que rijan en la actualidad una multiplicidad inmensa de procedimientos administrativos carentes de la más mínima uniformidad e, incluso, contradictorios entre sí.

Por ello, es urgente dotar a Nicaragua de una Ley de Procedimiento Administrativo que dé uniformidad y orden al sistema, y que establezca

PROYECTO DE

LEY DE RÉGIMEN JURÍDICO DE LAS

ADMINISTRACIONES

PÚBLICASY

PROCEDIMIENTO

ADMINISTRATIVO

COMÚN

BILL OF LEGAL

SYSTEM

FROM PUBLIC

ADMINISTRATION

ANDTHE COMMON

ADMINISTRATIVE

PROCEDURE 
un procedimiento general que sirva de cauce legal a la actuación de los órganos de la administración que quedarían compelidos a seguirlo para la realización y cumplimiento de sus tareas dentro del ámbito de su respectiva competencia.

Este vacío legal ha tratado de ser suplido a través de mecanismos diversos que, como ya dijimos, han provocado que rija toda una serie de procedimientos administrativos diseminados en un gran número de leyes especiales, en las que se han fijado procedimientos propios y diferentes entre sí, lo cual genera una enorme confusión e inseguridad jurídica para los administrados que carecen de una vía única y coherente desde la cual sustanciar sus pretensiones y peticiones frente al Estado desde su calidad de administrador.

La necesidad impostergable de una ley que regule esta área de actividad de la administración quedó plasmada en la Ley de Organización Competencia y Procedimientos del Poder Ejecutivo (ley 290), la cual en su artículo 46 establece que «lo no previsto sobre procedimiento administrativo [...] se regulará de conformidad con lo que establezca la ley de la materia».

Para el estado nicaragüense y para sus ciudadanos, sigue siendo una necesidad imperante contar con una norma jurídica que establezca el procedimiento administrativo común a toda la administración pública, que regule las formalidades para la formación, ejecución y revisión — dentro de la esfera administrativa - de los actos de la misma administración, que sirva de garantía jurídica a los administrados, y que evite el riesgo de que se adopten decisiones apresuradas, mal estudiadas y vejatorias a sus derechos.

El 22 de octubre de 1997, la Corte Suprema de Justicia presentó ante la Asamblea Nacional un proyecto de ley de procedimiento administrativo y de lo contencioso administrativo, cuyo primer capítulo estaba dedicado al procedimiento administrativo. En este proyecto de ley, por razones de técnica legislativa, se terminó por obviar el título primero. Dicha decisión, sin duda acertada, quiso que una materia tan relevante, como lo es el procedimiento administrativo, fuera objeto de regulación en un texto legislativo diferente, que diese una mayor entidad a la materia, como ocurre en los países más avanzados —el caso de España es paradigmático al respecto: dicha materia está regulada en la de Régimen Jurídico de las Administraciones Públicas y del Procedimiento Administrativo Común (ley 30/92) - .

En el año 2001, la bancada sandinista retomó este título y lo presentó como iniciativa de ley en la Asamblea Nacional. El referido proyecto contemplaba: (a) la finalidad de la ley como la eficaz satisfacción del interés público en el quehacer de la administración, debido a que su 
ámbito de aplicación es toda la actuación pública sujeta al Derecho administrativo; (b) la iniciación del procedimiento administrativo, que se puede producir de oficio o a petición de parte interesada; (c) la ordenación e instrucción del procedimiento administrativo, a fin de que se ocupe de que impulsen de oficio las normas de actuación administrativa, los medios de prueba y la audiencia del interesado; (d) la terminación del procedimiento administrativo por medio de resolución motivada, la notificación y la ejecutoriedad del acto administrativo y el silencio administrativo; (e) los recursos en la vía administrativa, incluyendo el de revisión y el de apelación; (f) las normas comunes al acto administrativo, la nulidad y anulabilidad de los actos; (g) el agotamiento de la vía administrativa; y (h) la irrevocabilidad de los actos administrativos declarativos de derechos en la vía administrativa.

A pesar del notable esfuerzo de los redactores de este proyecto de ley, era evidente que presentaba notables carencias. Para examinarlas, podemos distinguir dos grandes grupos de cuestiones. Por un lado, tenemos toda una serie de materias relativas al procedimiento administrativo propiamente dicho que fueron omitidas a pesar de su relevancia. Entre ellas, debemos destacar especialmente las siguientes: en los términos generales del mismo, se regulaba el procedimiento de manera muy breve; y, en términos particulares, no se encuentra referencia alguna a los reglamentos - muy extrañamente olvidados- Asimismo, no se contempla la revisión de oficio, ya que solo se regulan los recursos administrativos ordinarios, sin hacer referencia a los cauces y al régimen jurídico que debe seguir la administración para revisar — de propia iniciativa — las resoluciones que ella misma dicta.

Por otro lado, hay otra serie importante de carencias que tienen su origen en que el proyecto trata de enfrentarse tan solo a la regulación del procedimiento administrativo, sin contemplar el régimen jurídico básico de la administración. En países como España, se integra en un mismo texto legal la normativa reguladora del procedimiento administrativo y el régimen jurídico básico de la administración, con lo que se enfrenta a cuestiones como las reglas para la actuación de los órganos colegiados de la administración, la potestad sancionadora o la responsabilidad patrimonial de la administración, entre otras muchas materias.

La bondad de esta solución es difícilmente cuestionable, pues permite que la norma reguladora del régimen jurídico básico de la administración y del procedimiento administrativo se erija en una suerte de código administrativo básico, que facilita notablemente la aplicación del Derecho administrativo. Cuestión de gran relevancia, dado que las normas administrativas van a ser aplicadas primariamente por un número muy elevado de personas: los funcionarios públicos, la mayoría de los cuales no son en puridad expertos en Derecho administrativo. 
Si lo dicho anteriormente es válido para un país como España, con mayor razón aún lo es para un país como Nicaragua, carente de la tradición en el estudio y la aplicación del Derecho administrativo que tiene el país europeo antes citado. La reunión en un mismo texto legal de esa normativa básica facilitará notablemente el proceso de capacitación de los empleados públicos, y supondrá un factor inestimable a la hora de simplificar las tareas de estos, ya que contarán con una referencia básica cuando tengan dudas acerca del modo en el que puedan desarrollar sus tareas.

Por todo ello, los proyectos de ley presentados en los años 1997 y 2001, aunque constituyan un valioso aporte, consistieron solamente en un importante punto de partida para la elaboración del proyecto de ley que nos ocupa. Era preciso, entonces, elaborar — partiendo del mismo- un texto de mayor entidad, que fuese consultado y consensuado con los diferentes sectores de la sociedad civil y el Poder Ejecutivo, y co-redactado por los mejores técnicos internacionales en la materia.

Al establecer un sistema uniforme y armónico mediante una ley del procedimiento administrativo, se le proporciona al Estado administrador y al ciudadano administrado una relación directa con reglas claras, con lo cual se fortalece el Estado de Derecho, la gobernabilidad, la transparencia en el manejo de la cosa pública, así como también el cumplimiento del principio de legalidad y el de la seguridad jurídica.

\section{ELABORACIÓN DEL PROYECTO DE LEY}

La aprobación de una ley en la que se recoja el Régimen Jurídico de las Administraciones Públicas y el Procedimiento Administrativo Común en Nicaragua viene a dar respuesta a muchas y muy variadas necesidades, todas ellas de singular importancia para este país.

Para empezar, esta ley es el complemento imprescindible para completar el ordenamiento jurídico-administrativo de Nicaragua, que lenta, pero firme y laboriosamente se ha ido forjando durante los últimos años.

El funcionamiento del sistema administrativo -integrado en sus elementos principales por la Ley de Regulación de la Jurisdicción de lo Contencioso-Administrativa (ley 350), la Ley de Servicio Civil y de la Carrera Administrativa (ley 370), y la Ley de Contrataciones del Sector Público (ley 737) — quedaría seriamente perturbado si no se le adiciona este elemento central. Como se dijo, la estructura majestuosa sería, en realidad, una construcción excesivamente débil.

El propio legislador nicaragüense ha sido ya consciente de esta carencia al recoger en el artículo 2 de la Ley de la Jurisdicción Contenciosa un conjunto de definiciones básicas y varios de los principales y más 
perentorios elementos usualmente regulados por la Ley de Régimen Jurídico y de Procedimiento Administrativo. Esta insuficiente solución de urgencia supone un claro reconocimiento de la imposibilidad de que el ordenamiento jurídico administrativo pueda ponerse en marcha sin la aprobación del texto legal que nos ocupa. No puede prolongarse, sin embargo, el tiempo de esta situación interina e insólita en el Derecho comparado, pues la materia requiere de una regulación adecuada y suficiente.

El parlamento de Nicaragua prefirió limitarse a dar unos criterios mínimos, que permitieran poner en marcha la ley y su rápida ejecución y generó, con la reflexión y extensión debida, un texto legal independiente, como requiere la buena práctica legislativa: una Ley de Régimen Jurídico de las Administraciones Públicas y del Procedimiento Administrativo a la altura de las necesidades de este país. Todo indica, pues, que ha llegado el momento de emprender esa importante tarea.

La ley cuya elaboración se propugna viene a constituir una suerte de código básico para la regulación de las administraciones públicas en el que se recoge el régimen esencial de esta importante parte del sector público. Su aprobación conlleva, por ello, una importante labor uniformadora de su funcionamiento, que trae consigo una serie de ventajas relevantes.

En primer lugar, garantiza un trato similar, y, por lo tanto, no discriminatorio para los administrados, en la medida de que entra a definir un conjunto de garantías básicas de las que disfrutarán los ciudadanos en sus relaciones con cualquier administración pública, más allá de la distancia concreta ente el administrativo y la parte del territorio de Nicaragua en donde la persona se encuentre.

En segundo lugar, permite adoptar políticas, coherentes y unitarias, de reforma y modernización administrativa que, al actuar sobre una realidad en esencia unitaria, alcanzaran más que probablemente un mejor resultado.

Por último, una cuestión especialmente importante para Nicaragua es que se van a facilitar notablemente los procesos de capacitación y de actualización de conocimientos del personal al servicio de la administración.

Todo esto es consecuencia lógica de la importante simplificación que supone para el aprendizaje del Derecho administrativo la existencia de un marco básico común, cuyo conocimiento supone ya la adquisición de unas competencias notables para el ejercicio de las funciones administrativas. En cuanto a la normativa sectorial, el texto no contiene más que simples especificaciones de ese marco general que la adecúen a las características y necesidades específicas de cada sector.

PROYECTO DE

LEY DE RÉGIMEN

JURÍDICO DE LAS

ADMINISTRACIONES

PÚBLICASY

PROCEDIMIENTO

ADMINISTRATIVO

COMÚN

BILL OF LEGAL

SYSTEM

FROM PUBLIC

ADMINISTRATION

ANDTHE COMMON

ADMINISTRATIVE

PROCEDURE 
Las ventajas frente al sistema actual, que comporta la utilización de una multiplicidad de normas dispersas y carentes —en muchos casos de la mínima coherencia y unidad que requiere un sistema jurídico-, son evidentes.

Asimismo, las ventajas que supone para la implementación del nuevo régimen profesional que se ha fijado para los empleados públicos nicaragüenses son enormes. El proyecto va a poner a disposición del personal ya existente, así como de los candidatos a acceder al mismo, un acervo normativo esencial, que servirá de base para enjuiciar las capacidades de estos. De este modo, las tareas de selección de ese personal por parte de los órganos correspondientes de la función pública se facilitarán.

Por otra parte, la iniciativa constituye una importante garantía tanto para el mayor acierto de las decisiones administrativas, como para una correcta tutela de los derechos de los administrados. La normativa que nos ocupa encauza el funcionamiento de la administración pública y la obliga a seguir una línea de actuación ordenada y sistemática.

Frente a la arbitrariedad que se manifiesta en su acción en el momento presente, la propuesta de una ley como esta supone la articulación de un procedimiento adecuado y ordenado, que asegure una valoración suficiente de los intereses públicos y privados que están presentes en la toma de cada decisión. Lo que amplía notablemente la garantía de acierto de la decisión.

Esto provoca, además, una mayor confianza de la ciudadanía en el funcionamiento de la administración, en cuanto-como ya se dijo- permite a aquella conocer que esta no actúa de forma caprichosa y según sus deseos, sino siguiendo un discurrir prefijado y adecuado a las necesidades que tiene que resolver.

El proyecto de esta ley fomenta la participación de los ciudadanos en el desarrollo de las tareas administrativas y la transparencia en el desarrollo de estas. La ley que nos ocupa tiene entre sus principales contenidos la regulación de los procedimientos, trámites y derechos de los administrados a través de los cuales se les permite tomar conocimiento de la actuación desarrollada por la administración y hacer llegar, de forma efectiva, su voz a los administrados.

Con ello se diseña una acción administrativa más coherente y adecuada a los derechos de los administrados, ya que se han tenido en cuenta sus inquietudes y opiniones al diseñarla. A la par, se democratiza el funcionamiento de las instituciones públicas — para las cuales, de por sí, el ciudadano ya es un sujeto sometido a su poder de mando- , dotando al ciudadano de los derechos necesarios para que participe en la toma de decisiones que lo afectan. 
Como se dice, una iniciativa de este tipo favorece una correcta tutela del ciudadano frente a las decisiones que le perjudican. Al fijar un sistema de reclamaciones administrativas único, aplicable a todas las decisiones administrativas, se facilita el conocimiento por parte del ciudadano de los procedimientos y trámites a través de los cuales puede hacer valer sus intereses. La administración deja de ser así una realidad inaccesible, refugiada en una compleja y oscura normativa que lleva al ciudadano a desistir de la defensa de sus derechos, y pasa a convertirse en una realidad sujeta a controles claros y uniformes, a través de los que el administrado puede actuar fácilmente.

Es muy importante para el contexto jurídico nicaragüense, marcado por la existencia de importantes carencias normativas en muchos ámbitos, el carácter genérico del procedimiento administrativo que debe diseñar la ley. Es decir, no viene a fijar un procedimiento apto para una determinada materia o materias, sino un conjunto de trámites con los que se pueda armar un procedimiento adecuado a cada necesidad.

Esto permite que siempre que se cumplan las exigencias procedimentales mínimas que la ley impone para la toma de cualquier decisión administrativa, la normativa sectorial podrá establecer las especialidades que requiera cada concreto campo de acción administrativa. De esta manera, la aprobación de la ley uniforma, al establecer unas garantías mínimas para todo procedimiento, pero sin introducir ningún tipo de rigidez para el funcionamiento de la administración.

Sin embargo, ese diseño básico es suficiente para contar con un cauce de actuación coherente para la resolución de cualquier cuestión administrativa, aunque se carezca totalmente de una regulación específica sobre la materia.

\section{CONTENIDO Y ESTRUCTURA DEL PROYECTO DE LEY}

A mediados del año 2010, la Comisión de Justicia de la Asamblea Nacional, que preside el diputado José Palléis, formó una comisión técnica, presidida por quien escribe estas líneas, para redactar el proyecto de ley.

La Comisión de Justicia de la Asamblea Nacional nombró, de manera oficial, una comisión de asesores internacionales que estuvo conformada por destacados juristas, entre los que destacan Jesús González Pérez, José Luis Melián Gil, Jaime Rodríguez Arana, José Antonio Moreno Molina, Javier Barnes, Miguel Ángel Sendin García (España), Ernesto Jinesta Lovo (Costa Rica), Jorge Danós (Perú), Sven Muller-Grune (Alemania), Pedro Aberastury (Argentina) y Juan Pablo Cajarville (Uruguay). Todos ellos ayudaron de manera generosa y fueron guiados únicamente 
por el afán de que Nicaragua tuviera una legislación moderna en esta materia. A todos, les agradezco su colaboración.

El proyecto de ley fue consultado ampliamente con la Procuraduría General de la República de Nicaragua, la Fiscalía de la República de Nicaragua, la Corte Suprema de Justicia, el Consejo Superior de la Empresa Privada, el Ejército de Nicaragua, la Policía de Nicaragua, los catedráticos universitarios, varios abogados de prestigio, la red de consumidores y la sociedad civil.

Asimismo, se realizó un seminario en la sede de la Asamblea Nacional, en donde se recibió observaciones al proyecto. La Corte Suprema de Justicia, por medio de su vicepresidente, el doctor Marvin Aguilar, y la Procuraduría General de la República, por medio del procurador Hernán Estrada, realizaron acertadas observaciones al proyecto y contribuyeron a mejorar el proyecto de ley. Del mismo modo, el presidente de la Comisión de Justicia pidió un dictamen a la Escuela Gallega de Administración Pública.

En la actualidad, el proyecto de ley ha sido presentado a la primera secretaria de la Asamblea Nacional y, en los próximos meses, pasará al plenario para su discusión y posterior aprobación.

El título primero aborda el objeto, el ámbito de aplicación y las excepciones a la norma. Ahí, destacan por su novedad en los primeros preceptos de la ley las definiciones de los principales conceptos que utiliza la norma, así como el sometimiento a los principios generales de transparencia, participación, servicio con objetividad de los intereses generales, sometimiento pleno al Derecho y a la ley, autotutela, verdad material, buena fe, justicia e imparcialidad, legalidad y presunción de legitimidad, jerarquía normativa, control judicial, eficacia, economía, simplicidad y celeridad, informalismo, publicidad, impulso de oficio, gratuidad, proporcionalidad, consecución del interés público y protección de los derechos e intereses de los ciudadanos, igualdad, colaboración de la administración pública con los ciudadanos, participación y resolución, entre otros.

A continuación, la ley contiene la regulación de los órganos administrativos que constituye una completa ordenación de los mismos. También se establece el régimen de implicancia y abstención.

Las normas relativas a los interesados recogen las reglas sobre la capacidad de obrar, en especial los supuestos en que el Derecho administrativo se aparta del Derecho civil al regular la capacidad de obrar de las personas que se relacionan con la administración pública. La legitimación para intervenir en un procedimiento administrativo se reconoce no solo a los que ostentan derechos que resultaran directamente afectados por 
la decisión que en el mismo hubiere de dictarse, sino también a los titulares de intereses legítimos, personales y directos.

La Procuraduría de Derechos Humanos podrá actuar desde la iniciación del procedimiento administrativo — cuando así lo pida el interesadopara la defensa y tutela de las garantías constitucionales, del Estado de Derecho, de la seguridad jurídica de las personas y de la protección de los derechos humanos, incorporados en el artículo 46 de la Constitución Política. La Procuraduría General de la República podrá también participar en defensa de los intereses del Estado y velar por ellos.

Por lo que respecta a la posibilidad de que los interesados comparezcan en el procedimiento a través de representantes, el proyecto de ley la consagra en los términos más amplios, y otorga las máximas facilidades para acreditar la representación —que puede conferirse ante el órgano administrativo que instruye el procedimiento-.

En sus diversos capítulos, el proyecto de ley se refiere al estatus jurídico del ciudadano, lo que constituye uno de los aspectos fundamentales de la ley, y, a la vez, recoge un novedoso catálogo de derechos. Sin embargo, el proyecto tampoco se olvida de los derechos de los funcionarios y de los empleados públicos a ser tratados con respeto y deferencia.

En relación con las normas generales que deben presidir la actuación administrativa, se incide en las garantías jurídicas del Estado hacia los ciudadanos, al habilitar a la administración para adoptar cuantas medidas repercutan en la economía y favorezcan la celeridad y eficacia de los servicios. En cuanto al régimen de los actos administrativos, se determinan sus requisitos, y su eficacia y su invalidez — de forma completa y detallada-, con lo que se dota a la administración y a los interesados de una regla clara y concreta. Por lo que se refiere a términos y plazos, la ley resuelve con claridad todos los supuestos posibles, al dotar a los particulares de un completo instrumento de seguridad en sus relaciones con la administración.

El título segundo del proyecto de ley se dedica al procedimiento administrativo como cauce formal de la serie de actos en que se concreta la actuación administrativa para la realización de un fin.

El proyecto de ley regula la iniciación, instrucción y terminación como fases del procedimiento, ya que lo dota de la agilidad y eficacia que demanda la administración moderna.

El procedimiento podrá incoarse de oficio o a instancia de los interesados. En este último caso, cuando el escrito de iniciación no reuniera los requisitos exigidos, la ley impone al órgano competente la obligación de requerir al que lo hubiere firmado para que subsane la falta en el plazo 
de cinco días. Esto no es sino consecuencia del principio antiformalista que inspira el texto legal.

Iniciado un procedimiento, se faculta a la administración para adoptar las medidas provisionales que estime oportunas para la mejor defensa de los derechos de los particulares y de la propia administración, siempre que estas no causen perjuicios irreparables a los interesados ni violación de derechos amparados por las leyes.

En orden a la tramitación, el proyecto ha procurado por todos los medios la rapidez, pues la notificación viene a regularse sin caer en formalismos y teniendo en cuenta las nuevas técnicas electrónicas.

Los actos de instrucción constituyen, sin duda alguna, los más importantes del procedimiento, en cuanto tienden a proporcionar al órgano decisorio los elementos de juicio necesarios para una adecuada resolución. Ello no implica que en todo procedimiento se den todos los actos de instrucción regulados en la ley, pues —en muchos casos- bastarán las alegaciones aducidas por el interesado en su escrito inicial para que la administración, sin más trámites, dicte la resolución procedente.

Los interesados podrán aducir alegaciones en cualquier momento del procedimiento. Pero, aparte de este precepto general, la ley es la que finalmente regula el decisivo trámite de audiencia y vista.

La prueba se regula con gran amplitud y, además — a fin de garantizar debidamente los derechos de los interesados-, impone un período de prueba cuando la administración no tenga por ciertos los hechos aducidos por ellos o lo exija la naturaleza del procedimiento.

La terminación normal del procedimiento tiene lugar por resolución expresa del órgano administrativo competente, la cual decidirá todas las cuestiones que hayan planteado los interesados y aquellas otras derivadas del procedimiento.

El silencio de la administración será considerado como una decisión positiva exclusivamente en aquellos trámites en que la norma reguladora del específico procedimiento lo establezca. Quedan exceptuados de esta previsión los procedimientos de ejercicio del derecho constitucional de petición establecido en el artículo 52 de la Constitución Política de Nicaragua, también aquellos cuya estimación tuviera como consecuencia que se transfirieran al solicitante o a terceros facultades relativas al dominio público o al servicio público, así como los procedimientos de impugnación de actos y disposiciones en los que el silencio tendrá efecto desestimatorio.

Los actos administrativos producidos por silencio administrativo se podrán hacer valer tanto ante la administración como ante cualquier 
persona física o jurídica, pública o privada. Estos producen efecto desde el vencimiento del plazo máximo en el que debe dictarse y notificarse la resolución expresa, y su existencia puede ser acreditada por cualquier medio de prueba admitido en Derecho, incluido el certificado acreditativo del silencio producido que pudiera solicitarse del órgano competente. Una vez solicitado el certificado, este deberá emitirse en un plazo máximo de quince días.

Como modos especiales de terminación del procedimiento, la iniciativa de ley regula el desistimiento, la renuncia del derecho, la caducidad y el acuerdo, pacto o convenio.

La iniciativa de ley ordena también los medios de ejecución forzosa. Con carácter fundamental, consagra el principio del régimen administrativo que exige la decisión previa para que la administración pueda emprender cualquier actuación material. Dictada la decisión jurídica, la administración podrá proceder a la ejecución forzosa, a través de los medios idóneos para ello: apremio sobre el patrimonio, ejecución subsidiaria, multa coercitiva y compulsión sobre las personas.

La iniciativa de ley se ocupa por primera vez en el ordenamiento jurídico de Nicaragua de las potestades de la administración respecto de sus propios actos de un modo completo, al distinguir los supuestos de revisión de oficio y rectificación de errores materiales y de hecho.

Tras unas normas generales, la ley regula los distintos tipos de recursos: de revisión y de apelación. Esta ley unifica y simplifica los recursos administrativos existentes, los cuales son reducidos a estos dos recursos.

El título tercero regula el procedimiento para la elaboración de los reglamentos. El titulo cuarto regula el procedimiento para la elaboración de los planes territoriales y urbanísticos. El titulo quinto regula los principios básicos a los que debe someterse el ejercicio de la potestad sancionadora de la administración y los correspondientes derechos que de tales principios se derivan para los ciudadanos. Entre tales principios destaca el de legalidad, en virtud del cual el poder legislativo es el que debe fijar los límites de la actividad sancionadora de la administración; y el de tipicidad, manifestación, en este ámbito, del de seguridad jurídica — junto a los de presunción de inocencia y proporcionalidad—. La ley también detalla las diferentes fases del procedimiento sancionador.

El título sexto se ocupa de la responsabilidad de la administración pública e incorpora, de forma novedosa, la regulación de una materia estrechamente unida a la actuación administrativa y que constituye, junto al principio de legalidad, uno de los grandes soportes del Estado de Derecho y una garantía fundamental para los ciudadanos. 
Se consagra la regla general de indemnización de todas las lesiones que los ciudadanos sufran en sus bienes y derechos como consecuencia de mal funcionamiento de los servicios públicos, y, asimismo, se establece el régimen de responsabilidad de las autoridades y personal al servicio de las administraciones públicas.

El texto legal concluye con unas disposiciones finales en las que se establece una prudente vacatio legis, a fin de que tanto los funcionarios como los ciudadanos puedan adquirir un perfecto conocimiento de la misma, y también con vistas a que, en el seno de la administración, puedan adoptarse las medidas indispensables que su aplicación requiere. 